\title{
Algumas Reflexões Sôbre as Dificuldades da Administração Pública nos Paises em Vias de Desenvolvimento
}

\author{
Aryê Groberson \\ I I OBSERVAÇÕES PRELIMINARES
}

a) A importância da Administração Pública no processo de unificação nacional

UEM quer que se interesse pelos países em via de desenvolvimento encontrará uma quantidade de pesquisas e de trabalhos consagrados ao assunto. Tais paises que permaneceram desconhecidos durante séculos, adquiriram ràpidamente interêsse internacional. A conquista de sua independência efetuou-se num periodo relativamente curto. Acrescente-se que isso nem sempre se deveu à compreensão da dominação estrangeira, mas foi, freqüentemente o resultado de uma luta nacional do povo, pela independência. Bem depressa os referidos países ingressaram nas instituições internacionais, desenvolvendo suas relações do ponto-de-vista político e econômico. Sua importância tem, pois, aumentado e provocado o interêsse das grandes potências. Mesmo que se trate de um pais soberano, faltam-lhe, ainda, certas caracteristicas nacionais e pode-se dizer que persiste, o empenho no processo de unificação nacional.

Para a administração isso é importante, pois os interêsses, os pontos-de-vista, os costumes das diversas regiões são por vêzes obstáculos a certos empreendimentos nacionais. Animados pelo desejo de desenvolvimento rápido os países em questão têm necessidade de adquirir um nivel de desenvolvimento elevado dentro de poucos anos, enquanto os países desenvolvidos do mundo, na sua maioria, atingiram o estado atual em centenas de anos.

Isso cria um problema tríplice:

a) adquirir meios financeiros e materiais enormes para realizar os projetos nacionais essenciais; 
b) decidir quanto a ordem de prioridade dos mesmos, sendo certo que tal ordem de prioridade tem uma significação capital quanto à progressão do desenvolvimento nacional;

c) desenvolver os quadros nacionais, seja no domínio administrativo, seja no domínio técnico. É pràticamente impossível lançar grandes projetos, sem dispor do pessoal adequado; não se trata, pois, sòmente, de uma questão de recursos materiais e financeiros, mas, ao mesmo tempo, de uma questão de capacidades humanas a serem racionalmente utilizadas.

b) A concentração da elite intelectual e profissional no seio da Administração Pública

Pode-se dizer que na maioria dos países em via de desenjolvimento a elite intelectual e profissional acha-se concentrada quase exclusivamente nos organismos administrativos do país, sejam êstes gerais ou especializados. Dai duas observações importantes com referência às atividades humanas e às atividades profissionais; de início tais atividades no seio da administração alcançam, pràticamente, o conjunto da elite do país, seja ela adninistrativa, profissional ou politica. Conseqüentemente, fora dos organismos estatais não há organizações nem privadas nem públicas que centralizem as atividades da elite.

\section{c) Liderança administrativa}

Num passado, aliás muito próximo, a maioria dos quadros locais ocupava posições relativamente subalternas. A transformação do território dependente em Estado soberano não trazia, automàticamente, o conhecimento e a experiência administrativa necessários para gerir o Estado. Os quadros nacionais não estavam, pois, preparados para assumir e desempenhar, eficazmente, cargos que exigiam uma disciplina administrativa bastante ampla, e, doutra parte, faltava-lhes a necessária experiência operacional.

\section{d) A estrutura organizacional e os métodos de trabalho}

Pode-se constatar, fàcilmente, que as estruturas organizacionais e os métodos de trabalho do executivo mantiveram-se, na maioria dêsses paises, sem grandes reformas. É claro que uma administração regional baseada num método estrangeiro difere da administração de um Estado independente e soberano. Tal transformação exige, sem dúvida, uma série de reformas organizacionais bem evidentes. Ora, em realidade, a citada transformação não atingiu ainda a amplitude necessária para assegurar uma adminis-

Os corpos executivos na maioria dos países em questão ainda não se organizaram de maneira racional para responder às exigências de um rápido desenvolvimento. 
Essas dificuldades constituem sòmente uma parte do problema. A administração pública, produto da sociedade na qual atua, é, ao mesmo tempo, pràticamente, a vanguarda do desenvolvimento nacional. A ela cabe enfrentar as dificuldades, a primeira das quais ela encontra no seu próprio seio. Há, pois, não apenas um problema de liderança espiritual e política, mas também um de liderança administrativa.

\section{II - OBSTÁCULOS TÍPICOS NO FUNCIONAMENTO DA ADMINISTRAÇÃO}

É difícil e aleatório generalizar fenômenos típicos para um grupo de países. Permito-me, assim mesmo, generalizar alguns dêsses fenômenos, tomando por base observações diretas e indiretas da vida administrativa de tais países. Atentemos para o fato de que certas generalizações são extremamente importantes, seja em virtude de razões metodológicas, seja em virtude de razões práticas. Se podemos constatar fenômenos típicos num conjunto de países, isso nos pode servir como denominador comum.

Eis aqui cinco traços típicos no domínio administrativo, próprios a uma grande parte dos paises em via de desenvolvimento. Parece-me que um esfôrço se faz necessário, para a boa marcha administrativa, nos seguintes campos:

- Laços entre a administração e a população - Delegação da autoridade - Melhoria dos métodos de trabalho Coordenação - Aperfeiçoamento e formação de quadros.

\section{a) Laços entre a administração e a população}

Antes da independência e povo habitua-se a um comportamento passivo e por vêzes mesmo hostil à administração estrangeira do país. Há uma linha de demarcação entre NÓS (o povo) e ELES (a administração). Tal situação, compreensível durante a dominação estrangeira, deve desaparecer logo que possível, sem o que a fôrça criadora da unidade nacional correrá o risco de enfraquecer-se.

Acredito que a maior parte dos dirigentes dos paises em via de desenvolvimento tem sàbiamente, reconhecido a importância dos laços entre a administração central e o povo. Desenvolveram-se meios de comunicação, o que tem permitido que o povo se aperceba de que a independência não é apenas uma expressão da liberdade nacional, mas comporta, também, uma série de obrigações e de deveres assaz pesados.

É evidente que o conjunto dos trabalhos de um pais exige decisões e atividades de ordem nacional e, portanto, central. Paralelamente, incumbe à administração central encorajar e desen volver à administração regional e local. 
Encorajando os elementos construtivos a aceitarem uma responsabilidade ativa é que se consegue levar as populações locais a participarem das realizações nacionais. O fortalecimento dos laços entre a administração e a população pode ser efetivado através da participação ativa e comum na realização dos fins a serem alcançados.

Creio que os líderes políticos conhecem bem a importância dêsses laços, para assegurar a estabilidade do regime e os planos de desenvolvimento. Mas ao mesmo tempo os meios para se atingir a tal desiderato nem sempre são cuidadosamente escolhidos. Os processos de comunicação em massa ainda não se desenvolveram e a maioria da população ignora o que se passa no país. $\mathrm{O}$ assunto é delicado, pois a administração arrisca-se a voltar a ser um elemento estranho ao povo, e êste a novamente fazer a distinção entre NÓS (o povo) e ÊLES (a administração).

\section{b) Delegação da autoridade}

É óbvio que o conjunto do trabalho administrativo não pode ser executado por uma só pessoa. Torna-se imperativo, portanto, definir as tarefas e reparti-las entre os membros da organização ou da comunidade.

Uma nítida definição das tarefas evitará as duplicidades e as lacunas. O fato de uma pessoa ter uma tarefa a cumprir constitui uma obrigação. Essa não é apenas uma ação a desempenhar, mas implica a responsabilidade de fazê-lo da melhor maneira. A expressão formal dessa responsabilidade é a obrigação que tem o funcionário de prestar contas a seus superiores.

Devemos, ao mesmo tempo, atentar para o fato de que a responsabilidade atribuída ao funcionário não libera seu superior, pois é sempre sôbre o escalão superior que recai a responsabilidade global pelas atividades dos subordinados.

Um certo grau de autoridade está, evidentemente, ligado à responsabilidade pela tarefa. A origem da autoridade é sempre o individuo ou o corpo superior, remontando-se ao corpo eleitoral. Do mesmo passo é claro que os chefes de Estado não podem pràticamente exercer sua autoridade, pois é fisicamente impossivel que uma só pessoa ou um grupo limitado execute tôdas as funções, em todos os cantos do país, sem a assistência de uma série de administradores: Encontramo-nos, pois, diante da necessidade operacional de delegar a autoridade - processo essencial em cada administração.

Tanto mais centralizada a autoridade, tanto mais numerosas as deficiências da execução. Portanto, para que possa agir a administração deve ter a autoridade correspondente. Uma responsabilidade sem autoridade entravará a execução dos deveres confiados aos serviços ou à pessoa e, ao mesmo tempo, debilitará o processo de desenvolvimento. 
Parece-me que na maioria dos países em questão pode-se constatar uma excessiva concentração de autoridade nas cúpulas hierárquicas. Isso emperra a boa marcha da administração e desencoraja o senso de responsabilidade nos quadros.

Num país que acabou de conquistar a independência é. pràticamente, o corpo executivo que encarna a totalidade do poder. Ademais, a falta de estabilidade politica cria da parte dos chefes políticos a tendência de fortalecer seu dominio sôbre os órgãos administrativos da execução. Tal domínio prende-se a uma certa desconfiança em relação a outras, compreendidas entre elas colaboradores bastante próximos. O chefe procura manter-se a par dos acontecimentos que se verificam em seu serviço, situacão típica que abrange tôda a hierarquia até o Chefe de Estado. Na prática é grande o número de fatos e de atividades que sobem ao nível ministerial e, muitas vêzes ao do próprio Chefe de Estado.

Outra explicação para essa centralização extrema pode ser dada no plano psicológico. É pela autoridade que o funcionário fortalece seu senso de importância - uma certa compensação a seu «ego» que, no passado, não tinha possibilidade de exprimir-se.

Em cada escalão da chefia, qualquer que ela seja, o funcionário procura centralizar a autoridade, manifestação do seu poder.

Além das crenças de ordem politica e psicológica há razões de ordem técnica bem mais simp'es. As noções de divisão do trabalho fundada numa responsabilidade e numa autoridade adequada, ainda não estão suficientemente compreendidas e experimentadas na maior parte dessas administrações. O estado atual de centralização extrema contraria os interêsses do desenvolvimento nacional.

\section{c) Melhoria dos métodos de trabalho}

A determinação dos métodos e dos procedimentos responde a dois fins principais: primeiramente, o de executar as tarefas da maneira racional; em seguida, o de assegurar o bom funcionamento de todo o organismo.

Um método de trabalho e um procedimento não são racionais se não asseguram a coordenação entre as diversas atividades do serviço. O chefe de serviço antes de determinar ou mudar certos métodos de trabalho estudará em que medidas os métodos implantados não entram em contradição com outros existentes.

O ponto de partida do aperfeiçoamento de um método de trabalho repousa em dois elementos: $1^{\circ}$ ) para que serve o trabalho feito?; $2^{\circ}$ ) como melhorar o método de realização?

Se conseguimos economizar, através da melhoria dos métodos de trabalho, podemos nos permitir desenvolver outras atividades. pois os meios são limitados. 
É dever dos chefes encorajar seus subordinados a refletir sôbre suas tarefas, visando a eventuais aperfeiçoamentos.

Em realidade, são muito raras as modificações sistemáticas no sentido da melhoria das estruturas operacionais e dos métodos de trabalho. O que se observa freqüentemente é a coexistência de antigas fórmulas de organização e métodos, e meios avançados como as máquinas eletrônicas modernas.

São indispensáveis estudos sistemáticos nesse domínio, mas com a condição de que sejam efetivamente seguidos. Testemunhei vários dêsses estudos administrativos interessantes que permaneceram sem a menor utilização. Será, provàvelmente, preciso que se renuncie à procura de modelos administrativos ótimos e se cuide de realizações escalonadas.

\section{d) Coordenação}

A especialização orienta a atividade da administração no sentido de uma certa «autarquia», de uma tendência do espirito para a ação autônoma. Isso é característico para os ministérios e os serviços governamentais, pois cada um dêles tem seus objetivos particulares a atingir. Sabemos que a fôrça da administração depende do elo mais fraco da cadeia.

Há, também, o perigo de cada célula da administração vir a desenvolver - se à parte, sem coordenação com as atividades das outras. E o conjunto das atividades de tôdas as células que produz uma administração eficiente.

A coordenação tem, pois, por objeto principal servir ao mesmo tempo de regulador, de «contrapêso» às tendências separatistas que a especialização pode desenvolver.

Não é por acaso que a função de coordenação é objeto de numerosas pesquisas e estudos. Há mesmo autores que consideram essa função crítica da administração constatando que se pode chegar a resultados melhores com funcionários de nível relativamente baixo, mas com uma coordenação eficiente, do que com funcionários de alto nivel mas com uma coordenação fraca.

Entre as expressões concretas da coordenação podem ser citados os contatos quotidianos entre os dirigentes, com vistas à permuta de informações e consultas. A troca de opiniões sôbre a maneira de executar, o trabalho é a base da melhor coordenação.

Num plano mais oficial, citamos, nessa perspectiva, os comitês interministeriais ou interserviços, permanentes ou ad hoc.

Ainda que, muitas vêzes, sejam de ordem puramente consultativa tais instâncias atuam com muita eficiência no processo de coordenação. Como se vê, a coordenação depende muito da boa compreensão mútua: quanto melhor se compreende o ponto-devista alheio, mais inclinado se está a colaborar. 
As relações diretas entre os membros da organização dinamizam também a administração, pois é muito mais complicado alcançar a compreensão e a coordenação por escrito do que através de um contato direto e verbal entre os interessados. Êste gênero de contatos pode também conduzir ao fortalecimento do espírito de equipe, elemento tão importante na vida da administração.

\section{e) Aperfeiçoamento e formação dos quadros}

Os melhores planos de desenvolvimento econômico não serão exeqüiveis sem o apoio criador do pessoal. Isso é essencialmente válido nos países em via de desenvolvimento, cuja elite, em geral, está concentrada na administração.

Parece-me, pois, que os dirigentes de tais países defrontam-se com esta primeira dificuldade: a formação e o aperfeiçoamento dos quadros nacionais. Tive ocasião de reunir no próprio local documentação referente às atividades das escolas, das instituições e dos centros nacionais de formação administrativa, em certos países jovens, seja de língua inglêsa, seja de língua francesa. É característico que nos programas de estudos dêsses organismos a ênfase recaia, particularmente, nos temas de direito e em certas técnicas elementares do trabalho de escritório. Conseqüentemente, o aluno ou estagiário egresso de tal centro possui conhecimentos e aptidões jurídicas relativamente bons, mas muito pouco conhecimento de administração e nenhuma preparação em matéria de gestão administrativa. Acredito, também, que a predominância dos assuntos jurídicos no programa de ensino cria uma atitude de exagerado formalismo no funcionamento quotidiano da administração; muitos papéis e documentos, muito papelório administrativo, formal e inútil.

Êsses centros de formação e aperfeiçoamento são o berço dos quadros nacionais; a administração será, pràticamente, determinada pelo nivel e pela capacidade dos jovens que por êles passam. Sem subestimar a importância da educação jurídica, não creio que ela seja suficiente. $\mathrm{O}$ que os quadros administrativos dos países em questão necessitam é fortalecer sua educação social e administrativa pròpriamente dita, mediante o desenvolvimento das capacidades analíticas da tomada de decisão, o conhecimento dos processos administrativos de base, a compreensão dos mecanismos humanos e os métodos de comando, ai compreendida, a aptidão para aperfeiçoar os métodos de trabalho. Trata-se, pois, de certas reformas de base no ensino administrativo e, paralelamente, nos seus métodos. Os métodos atuais, na maioria dos centros, são de caráter passivo, enquanto que no domínio administrativo e, com vistas ao desenvolvimento da personalidade, os métodos de ensino ativo me parecem mais adequados.

Para cada um dos cinco elementos que escolhi como provas da franqueza da administração pública nos países em via de 
desenvolvimento se impõe uma melhora radical. Mas ao mesmo tempo me parece que êles se acham estreitamente relacionados entre si, e que seria quase impossivel chegar a um resultado sem levar em conta essa interdependência.

In «La Revue Administrative» $\mathrm{n}^{0}$ 103, págs. 101 e segs. Tradução de Thomás de Vilanova Monteiro Lopes. 